\title{
DEBAIXO DA CAMA
}

Maurício Rodrigues de Resende ${ }^{1}$

\section{RESUMO}

O presente trabalho trata de uma simulação de escavação, feita dentro de um apartamento, mais especificamente no dormitório, onde o sítio a ser escavado é uma cama. Obviamente, não serão abordadas técnicas usadas durante uma escavação real, mas sim o pensar arqueológico. Ou seja, a priori, o trabalho reside na teoria e metodologia da Arqueologia, passando por todas as etapas, desde o planejamento do projeto até a divulgação dos resultados obtidos na pesquisa.

Palavras-chave: arqueologia; debaixo da cama; fundamentos da prática arqueológica

\section{ABSTRACT}

This work is a simulation of excavation, made inside an apartment, more specifically in the room where the site to be excavated is a bed. Obviously, they will not be addressed techniques used during an actual excavation, but the archaeological thinking. That is, a priori, the work lies in the theory and methodology of archeology, through all stages, from project planning to the dissemination of the results obtained in the research.

Keywords: archeology; under the bed; foundations of archaeological practice

\section{RESUMEN}

Este trabajo es una simulación de la excavación, realizada dentro de un apartamento, más concretamente en la habitación donde el sitio para ser excavado es una cama. Obviamente, no se tratarán técnicas utilizadas durante una excavación real, pero en el pensamiento arqueológico. Esto es, a priori, la obra radica en la teoría y metodología de la arqueología, a través de todas las etapas, desde la planificación del proyecto hasta la difusión de los resultados obtenidos en la investigación.

Palabras-clave: arqueología; debajo de la cama; fundamentos de la práctica arqueológica

\section{INTRODUÇÃO}

A arqueologia é uma disciplina que habita o imaginário humano quase sempre em uma única abordagem: a versão romântica. Descoberta de artefatos preciosos, estonteantes tesouros e civilizações perdidas no tempo formaram uma concepção quase caricata da ciência arqueológica, muitas vezes influenciada pela indústria cinematográfica norte-americana. Dentro deste universo romântico, a escavação aparece como a principal (senão a única) maneira de executar a arqueologia.

${ }^{1}$ Pós-graduando em Arqueologia na Universidade de Santo Amaro - UNISA 


\section{Revista de Arqueologia Pública}

Apesar de inúmeros estudiosos e profissionais se posicionarem sobre esta visão equivocada, a eterna imagem de Indiana Jones povoa o pensamento do público em geral, conforme abordou Pedro Paulo Funari (2003).

A arqueologia é, acima de tudo, uma ciência com teoria e metodologia próprias. Possuindo uma enorme interdisciplinaridade, ela traz à luz questões sobre idos tempos e procura, acima de tudo, saber como o homem se relacionava em determinada época, espaço e contexto. Para achar "pegadas humanas escondidas na areia", o arqueólogo tem que seguir determinados passos, calcados nas já citadas teoria e metodologia, com as quais pouco a pouco, é revelado um vislumbre sobre os homens que já viveram neste mundo. Caminhar fora desses "passos" pode significar colocar em risco um trabalho bem feito.

O processo científico é imprescindível para os que desejam rumar no mundo arqueológico. Afinal, neste mundo, os pensamentos vão muito além de Indiana Jones...

\section{PLANEJAMENTO}

O sítio escolhido para escavação encontra-se debaixo de uma cama, situada em um dormitório do apartamento 92 no Edifício llha Bela, na Rua das Flores, n. 278, Bairro Jardim das Flores, na cidade de Osasco, região metropolitana de São Paulo. A escolha do lugar justifica-se por ser, em partes, um local de descarte. Os objetos cotidianos usados por uma família geralmente encontram-se à sua vista ou, no máximo, em locais de fácil acesso. Os objetos que ficam debaixo da cama, por sua vez, por não estarem em um local de fácil acesso, podem significar que não são usados frequentemente, ou que são material de descarte.

O objetivo deste trabalho foi analisar os artefatos encontrados nesse sítio, para conhecer os costumes dos habitantes desse apartamento e pesquisar o motivo pelo qual os utensílios em análise foram deixados de lado. Os objetos algum dia podem ter sido de uso constante e contínuo, mas que devido à tecnologia ou outros motivos, foram descartados. Ou então, podem ter sido de uso não contínuo, mas de tal importância que não foi feito um "descarte definitivo" (ou seja, em um local longe da residência).

Inicialmente, foi feito um trabalho de prospecção ao redor do sítio denominado Cama, localizado no dormitório, a fim de averiguar se existiam indícios de artefatos no local. Após este procedimento, foi feita a delimitação da área a ser escavada. Posteriormente a essa fase, iniciou-se o processo de escavação para observar as camadas estratigráficas. Após a fase de escavações, os objetos retirados foram limpos, organizados, registrados e analisados para posterior preparação de relatórios. O trabalho foi finalizado com a divulgação do material em local público, a fim de interagir com a população local sobre os achados, enfatizando a importância do resgate desta memória e da troca de ideias entre os trabalhadores do sítio e a população. 


\section{Revista de Arqueologia Pública}

Inicialmente, foi feita uma pesquisa sobre quem morava no apartamento onde está localizado o sítio "Cama" (Fig. 1). Foi averiguado que moravam duas pessoas, um homem e uma mulher, possivelmente casados, de classe econômica média. Não foram encontrados indícios de brinquedos ou quaisquer artefatos infantis, dando a ideia de que crianças não moravam no recinto. Os moradores do imóvel tinham costumes e consumo de acordo com sua faixa econômica, claramente especificada pelo tipo de apartamento onde moravam e pela localização do imóvel. Um apartamento com um custo mais elevado apresentaria dimensões maiores e opções como piscinas, quadras esportivas, salões de ginástica, etc., o que não corresponde ao caso desse edifício. Suas dimensões e status correspondem a um apartamento de classe média. Outro parâmetro para definir a classe social dos moradores do apartamento é a região do imóvel: localizado próximo à zona central de Osasco, o perfil do imóvel não corresponde a outros que se situam em bairros considerados "nobres".

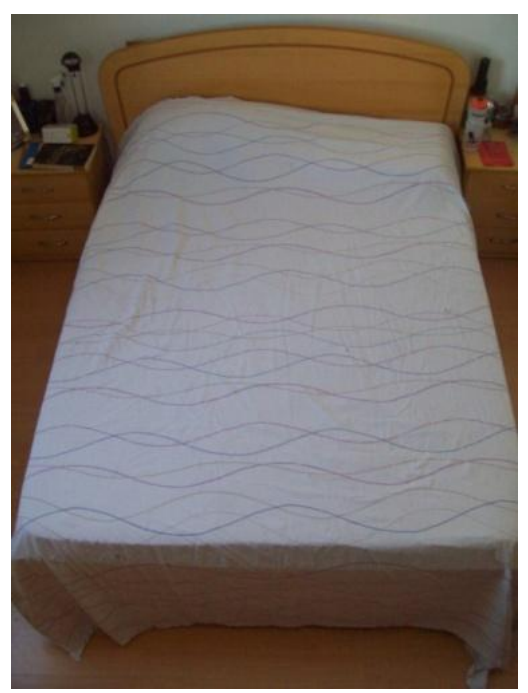

Figura 1 - Sítio "Cama”

Após esta fase inicial de pesquisa, iniciou-se a prospecção no ambiente dormitório, com o intuito de se procurar indícios do material usado pelas pessoas que moraram no local. Na parte norte do sítio, durante o trabalho de prospecção, não foi encontrado nenhum objeto ou indício. Na parte noroeste, foi evidenciado um objeto, que corresponde a um carregador de telefone celular (Fig. 2), situado entre o criado-mudo e a cama. Na parte sudoeste do sítio foi encontrado o segundo objeto, que corresponde a uma peça artesanal (Fig. 3), em forma de espantalho, feito de tecido, feltro e palha. Possivelmente, o objeto deve ter sido usado como peso ou encosto, pois continha areia na parte inferior. 


\section{Revista de Arqueologia Pública}

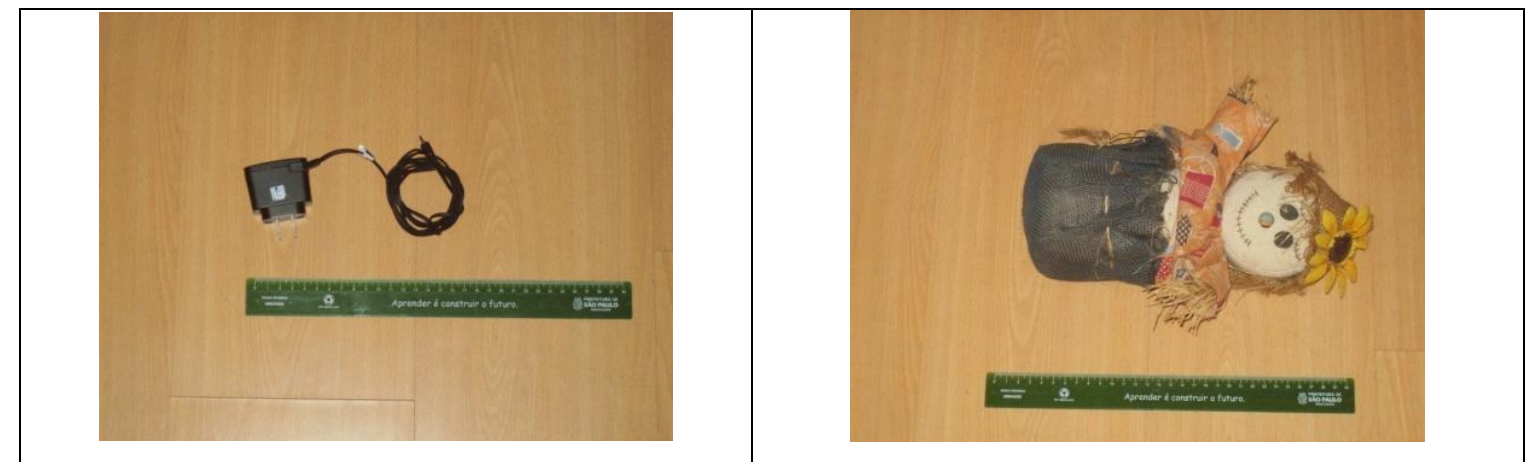

Figura 2 - Carregador de celular

Figura 3 - Peça artesanal em forma de espantalho

Os dois objetos encontrados, por serem tão distintos entre si, sugerem a possível diversidade que possa ser encontrada no sítio, remetendo a um padrão de consumo diversificado. $O$ achado de tais objetos justifica a escavação, por deixar clara a possibilidade de haver outros objetos no sítio "Cama". Partimos então, para as próximas etapas da pesquisa: a escavação e registro.

\section{ESCAVAÇÃO E REGISTRO}

A abordagem da escavação a ser escolhida depende das condições de cada sítio a ser explorado. Conforme Drewett (1999), a abordagem da escavação varia de local para local, dependendo da estrutura do sítio. Como o sítio "Cama" é relativamente pequeno, será feita uma escavação por quadrículas, demonstradas fisicamente somente após a retirada da camada "estrado". Na primeira fase da escavação foram inicialmente retiradas as camadas estratigráficas até que se chegasse ao ponto onde poderia haver artefatos. Ao retirar a primeira camada denominada "lençol" do sítio "Cama", entramos em contato direto com a camada denominada "colchão". Como não apareceram quaisquer objetos, a próxima fase foi a retirada da camada colchão, que também não apresentou material para a pesquisa.

A próxima camada, denominada "estrado", também não apresentou objetos para a pesquisa. Esta camada tem como principal intuito sustentar o colchão no sítio "Cama", deixando-o elevado acima do chão por alguns centímetros. Após a retirada da camada estrado, chegamos à camada "chão", onde foram executadas as escavações. Para uma melhor delimitação, o sítio foi então dividido em quatro quadrículas (Figs. 4, 5, 6 e 7). 


\section{Revista de Arqueologia Pública}

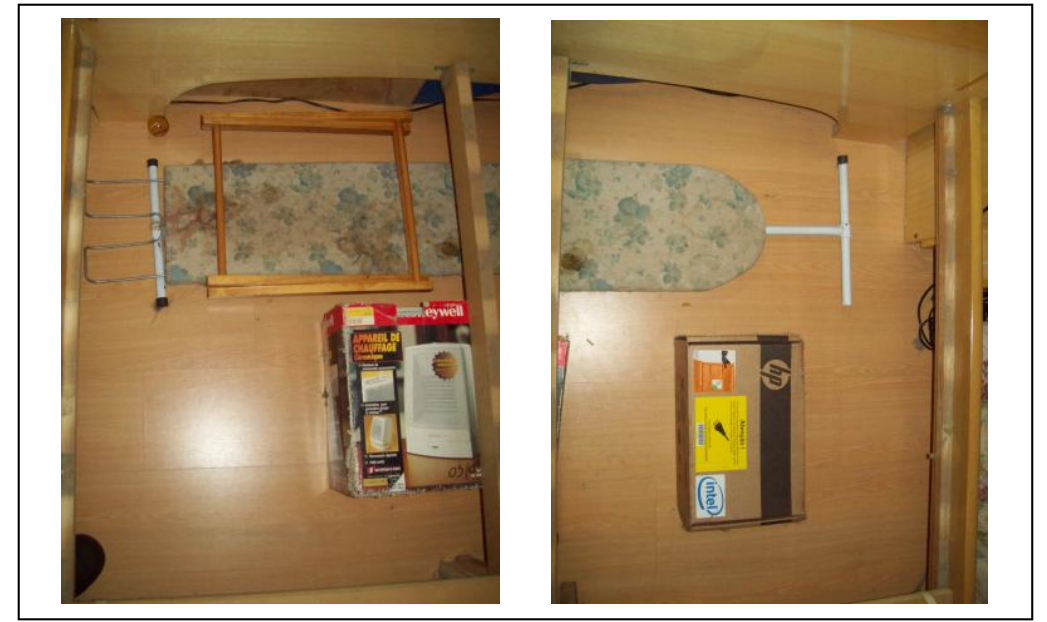

Figura 4 - Quadrícula 1

Figura 5 - Quadrícula 2

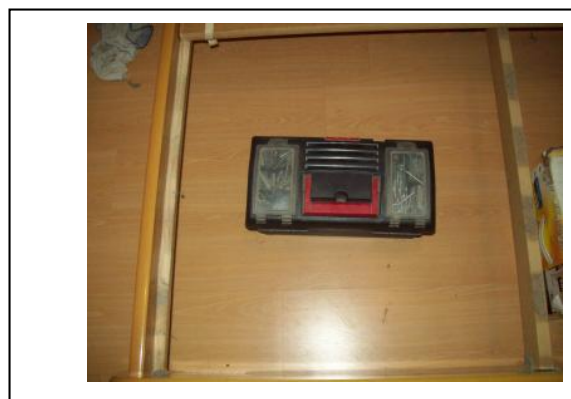

Fig. 6 - Quadrícula 3

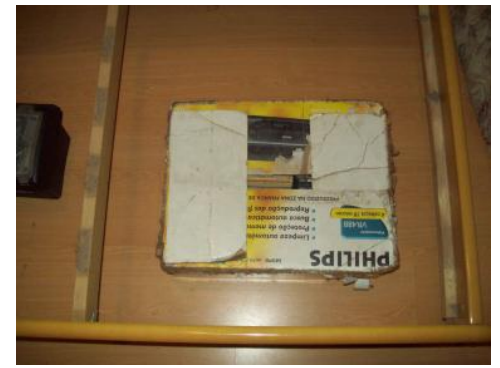

Fig. 7 - Quadrícula 4

Após chegar-se à camada chão, iniciaram-se as escavações e foram retirados os objetos encontrados (Tabela 1). Os objetos foram então limpos, catalogados e registrados (Tabela 2).

\begin{tabular}{|c|c|}
\hline $\begin{array}{l}\text { Quadrícula } 1: \\
1 \text { tábua de passar roupa } \\
1 \text { tripé de madeira } \\
1 \text { bola emborrachada } \\
1 \text { caixa contendo aquecedor }\end{array}$ & $\begin{array}{l}\text { Quadrícula 2: } \\
1 \text { caixa contendo várias fitas cassetes }\end{array}$ \\
\hline $\begin{array}{l}\text { Quadrícula 3: } \\
1 \text { caixa de ferramentas }\end{array}$ & $\begin{array}{l}\text { Quadrícula 4: } \\
1 \text { caixa contendo vários CDs }\end{array}$ \\
\hline
\end{tabular}

Tabela 1 - Material das quadrículas 


\section{Revista de Arqueologia Pública}

\begin{tabular}{|c|c|c|c|}
\hline Objeto & Sítio & Localização & Registro \\
\hline $\begin{array}{c}\text { Tábua de passar } \\
\text { roupas }\end{array}$ & Cama & Quadrícula 1 & CAM1 \\
\hline Tripé de madeira & Cama & Quadrícula 1 & CAM2 \\
\hline Bola emborrachada & Cama & Quadrícula 1 & CAM3 \\
\hline Aquecedor & Cama & Quadrícula 1 & CAM4 \\
\hline $\begin{array}{c}\text { Caixa com fitas } \\
\text { cassete }\end{array}$ & Cama & Quadrícula 2 & CAM5 \\
\hline $\begin{array}{c}\text { Caixa de } \\
\text { ferramentas }\end{array}$ & Cama & Quadrícula 3 & CAM6 \\
\hline Caixa com CDs & Cama & Quadrícula 4 & CAM7 \\
\hline
\end{tabular}

Tabela 2 - Discriminação e registro do material encontrado nas quadrículas

\section{DETERMINAÇÃO DO POTENCIAL DE ANÁLISE E ORGANIZAÇÃO}

\section{Triagem}

Nesta fase, após a escavação, foi feita uma triagem para determinar quais materiais seriam analisados, e quais seriam descartados. Na Tabela 3, são discriminados os objetos encontrados, 0 registro das camadas e os resultados da triagem:

\begin{tabular}{|c|l|l|l|}
\hline $\begin{array}{c}\text { Objeto } \\
\text { roupas }\end{array}$ & Registro & \multicolumn{1}{|c|}{ Triagem } & \multicolumn{1}{c|}{ Argumento } \\
\hline Tábua de passar & CAM1 & $\begin{array}{l}\text { Objeto será alvo } \\
\text { de estudo }\end{array}$ & $\begin{array}{l}\text { Objeto não condiz } \\
\text { no local onde foi } \\
\text { encontrado. Uma } \\
\text { análise é } \\
\text { necessária }\end{array}$ \\
\hline Tripé de madeira & CAM2 & $\begin{array}{l}\text { Objeto será alvo } \\
\text { de estudo }\end{array}$ & $\begin{array}{l}\text { Tal objeto pode ter } \\
\text { inúmeros fins, } \\
\text { talvez impossíveis } \\
\text { de serem } \\
\text { diagnosticados. O } \\
\text { objeto, porém, não } \\
\text { condiz no local } \\
\text { onde foi } \\
\text { encontrado }\end{array}$ \\
& & & \\
& & &
\end{tabular}




\section{Revista de Arqueologia Pública}

\begin{tabular}{|c|c|c|c|}
\hline Bola emborrachada & CAM3 & $\begin{array}{l}\text { Objeto será alvo } \\
\text { de estudo }\end{array}$ & $\begin{array}{l}\text { Objeto não condiz } \\
\text { no local onde foi } \\
\text { encontrado. É } \\
\text { necessária uma } \\
\text { análise }\end{array}$ \\
\hline Aquecedor & CAM4 & $\begin{array}{l}\text { Objeto será } \\
\text { descartado }\end{array}$ & $\begin{array}{l}\text { Tal objeto é } \\
\text { deveras comum e } \\
\text { seu uso é } \\
\text { conhecido. Não é } \\
\text { necessária uma } \\
\text { análise }\end{array}$ \\
\hline $\begin{array}{c}\text { Caixa com fitas } \\
\text { cassete }\end{array}$ & CAM5 & $\begin{array}{l}\text { Objeto será alvo } \\
\text { de estudo }\end{array}$ & $\begin{array}{l}\text { Objeto não condiz } \\
\text { no local onde foi } \\
\text { encontrado. É } \\
\text { necessária uma } \\
\text { análise }\end{array}$ \\
\hline $\begin{array}{c}\text { Caixa de } \\
\text { Ferramentas }\end{array}$ & CAM6 & $\begin{array}{l}\text { Objeto será } \\
\text { descartado }\end{array}$ & $\begin{array}{l}\text { Tal objeto é } \\
\text { deveras comum e } \\
\text { o motivo de seu } \\
\text { uso é conhecido. } \\
\text { Não é necessária } \\
\text { uma análise }\end{array}$ \\
\hline Caixa com CDs & CAM7 & $\begin{array}{l}\text { Objeto será alvo } \\
\text { de estudo }\end{array}$ & $\begin{array}{l}\text { Objeto não condiz } \\
\text { no local onde foi } \\
\text { encontrado. É } \\
\text { necessária uma } \\
\text { análise }\end{array}$ \\
\hline
\end{tabular}

Tabela 3 - Triagem

\section{Descarte}

A seleção de descarte foi feita a partir do entendimento da funcionalidade dos componentes do conjunto analisado. Neustupný (1993, p. 45), citando o arqueólogo alemão H. J. Eggers, diz que "o registro arqueológico foi reduzido tanto qualitativa como quantitativamente em relação à cultura vivente, o que representa uma seleção. Eggers considera que a cultura 'morta' é mais ou menos um subconjunto de itens selecionados pela cultura vivente". Da mesma maneira que os antigos moradores 


\section{Revista de Arqueologia Pública}

selecionavam os objetos à "cultura vivente", o arqueólogo também selecionará o que será analisado. O objetivo inicial desta pesquisa consiste em analisar objetos que possam "dizer" como os moradores do apartamento viviam. Portanto, seguindo o pensamento de Eggers, os objetos que ainda têm "perguntas a responder" devem permanecer à luz da análise e os outros objetos, que por si só encerram suas perguntas sobre funcionalidade, não serão analisados. O primeiro objeto a ser descartado, o "Aquecedor", foi escolhido pelo teor de sua funcionalidade. $O$ artefato delimita-se no seu uso, pois se entende que o aparelho tem uma determinada utilidade de aquecer ambientes, apenas em épocas de temperaturas mais baixas, não precisando estar armazenado em um local de uso contínuo em outras épocas do ano. Vale a ressalva que a caixa plástica do aquecedor apresentava intervenção de mordidas e arranhões de algum animal. O segundo objeto a ser descartado, a "Caixa de ferramentas" apresenta um argumento parecido com o anterior: o seu uso não frequente possibilitou seu armazenamento em um local de pouco acesso aos moradores do apartamento. Ferramentas são utilizadas normalmente quando algum objeto em específico danifica-se e exige reparo. No contexto consumista em que nossa sociedade se insere, é considerável ponderar que muitas vezes o morador prefere comprar um novo artefato ao invés de consertá-lo, deixando as ferramentas com um uso cada vez menos frequente. Também se pode discernir que o apartamento não apresenta espaço ou locais adequados para armazenar ferramentas de uso contínuo. Então, o melhor local para deixar estes objetos armazenados seria uma área de uso pouco frequente. Deste ponto de vista, tais objetos não foram analisados, pois há um entendimento de sua funcionalidade e utilização dentro dos limites do sítio "Cama".

\section{Objetos com potencial para estudo}

Quando o artefato passa por uma transformação espacial (NEUSTUPNÝ, 1993) é preciso entender em qual contexto ele se encaixa. Deste ponto de vista, os objetos restantes "nos fazem perguntas" sobre os motivos de sua localização no sítio e as razões de serem transformados em descarte, já que aparentemente, alguns deles apresentam características de uso contínuo.

O primeiro artefato, a "Tábua de passar roupas", um objeto de uso frequente, normalmente estaria em um local mais acessível. O motivo de estar no sítio "Cama" levanta uma série de questionamentos: Por que tal objeto está neste local de descarte? Por que aparece em tal estado de deterioração? Por que, se não era de uso diário, não fora descartado definitivamente? Por que o artefato apresenta sinais de ter sofrido ações de animais, como arranhões e mordidas? Tais questões merecem um estudo mais apropriado.

O segundo artefato, o "Tripé de madeira", pode ter sido uma estrutura de uma infinidade de objetos. Porém, por estar separado do resto de seu conjunto, perdeu sua funcionalidade original. $\mathrm{O}$ objeto também não possui uma estrutura deveras resistente ou adaptável para outros fins. Fica então a indagação do motivo do objeto encontrar-se nos domínios do sítio Cama, e não ter sido descartado definitivamente. 


\section{Revista de Arqueologia Pública}

O terceiro objeto, a "Bola emborrachada", é talvez o mais intrigante do conjunto a ser analisado. Como foi dito anteriormente, o apartamento onde se localiza o sítio Cama não demonstrou ter abrigado crianças em seu recinto, somente adultos. O único objeto encontrado que pode ser relacionado ao universo infantil é este brinquedo. O motivo deste artefato estar isolado (de outros com a mesma tipologia) no recinto e ainda em uma área de descarte levanta indagações que merecem ser investigadas. Assim como a tábua de passar roupas, o objeto parece ter sofrido "mutilações" por animais.

O quarto e o quinto objetos a serem analisados, "Caixa com fita cassete" e "Caixa com CDs", caracterizam-se por serem objetos cotidianos, supostamente de uso frequente. Apesar disso, os elementos ficaram localizados dentro dos limites do sítio "Cama", tornando-se objetos com acesso mais restrito. As caixas originais dos objetos são de papelão e, assim como outros objetos do conjunto, apresentam intervenções provocadas por animais. Tais artefatos devem então, ser melhor avaliados.

\section{Classificação}

Os objetos que não foram descartados são classificados da seguinte maneira:

\begin{tabular}{|c|c|c|}
\hline ARTEFATOS & ARTEFATOS DE LAZER & $\begin{array}{c}\text { ARTEFATOS } \\
\text { RELACIONADOS À } \\
\text { MOMÉSICA }\end{array}$ \\
\hline $\begin{array}{c}\text { Tábua de passar roupas } \\
\text { (CAM1) }\end{array}$ & Bola emborrachada & Caixa de CDs \\
(CAM3) & (CAM5) \\
\hline Tripé de madeira & & Caixa de fitas cassete \\
(CAM2) & & (CAM7) \\
\hline
\end{tabular}

Tabela 4 - Classificação

Alguns objetos, em particular, as fitas cassete e os CDs, apesar de estarem classificados na mesma categoria, não podem se submeter à categoria de associados, conforme define Childe. $O$ autor defende que o termo associados sugere um uso simultâneo, o que não pode acontecer neste caso entre fitas cassete e CDs: "uma mera justaposição física não garante associação" (Childe, 1969, p. 56). Devemos nos atentar que as fitas cassete e os CDs pertencem a tempos históricos diferentes, existindo a possibilidade de não terem sido usados simultaneamente, conforme será abordado adiante. Porém, é aconselhável separá-los dentro de uma mesma classificação, tendo em vista que ambos os modelos pertencem a tipologias "musicais". Assim, distanciando-se um pouco do esquema de tipologia tradicional, foi preferível adotar o pensamento de Trigger (2004), que disserta sobre a criação de novas classificações assim que surgem novos problemas.

Ainda sobre as "plataformas musicais" descobertas no sítio, é necessário enfatizar o estado em que as caixas se encontravam. Feitas de papelão, tanto a caixa dos CDs quanto as das fitas 


\section{Revista de Arqueologia Pública}

cassete apresentavam-se em avançado estado de deterioração e com inúmeros sinais de depredação. As marcas assemelham-se a arranhões e mordidas causados por animais.

As outras tipologias referem-se a utensílios domésticos e objetos de lazer. Na primeira tipologia, a tábua de passar roupas e o tripé de madeira estão totalmente fora de seus "lugares comuns", conforme abordado anteriormente. A tábua de passar roupas, em especial, apresenta claros sinais de deterioração e depredação animal, assim como as caixas. O outro objeto encontrado, a bola emborrachada, também contendo sinais de depredações similares a mordidas, apresenta-se fora de seu contexto, e foi classificada como "objeto de lazer".

O material ficará em salvaguarda em outro cômodo do apartamento, para melhor ser analisado e estudado.

\section{ANÁLISE E RESULTADOS}

Os primeiros objetos analisados pertencem à tipologia de Artefatos Domésticos, subdivididos em Tábua de passar roupas e Tripé de madeira. Posteriormente, foram analisadas as outras duas tipologias: Artefatos de Lazer e Artefatos Relacionados à Música (subdividos em Caixa de CDs e Caixa de fitas cassete).

\section{Tábua de passar roupas}

O artefato "Tábua de passar roupas", como já dito anteriormente, é comumente um objeto de uso contínuo, talvez até diário. Sendo assim, deveria estar em local mais acessível aos moradores da residência. O envoltório de pano ao redor da prancha de madeira apresentava-se desfiado, e a prancha com sinais de depredação animal, como mordidas e aranhões. Ainda vale ressaltar o processo de enferrujamento em sua estrutura metálica. Tais condições demonstram que o utensílio não era mais utilizado pelos habitantes do apartamento. Talvez os moradores tenham adquirido um novo objeto em substituição à tábua, com características tecnológicas superiores. Outra possibilidade é a substituição da tábua por outro objeto cotidiano, presente no apartamento, com maior praticidade (desconhecido nesta pesquisa) ou então, devido ao tamanho diminuto da residência, não houvesse outro lugar para guardá-la e, assim, permaneceu afastada dos olhos dos habitantes da residência na área limítrofe do sítio. Tais fatores, entretanto, não explicam o motivo do objeto não ter sido descartado de maneira definitiva. Apesar da impossibilidade de estabelecer uma datação absoluta, pode-se concluir que este objeto pertenceu ao período de tempo em que os moradores se estabeleceram na residência.

\section{Tripé de madeira}

Assim como para o objeto anteriormente apresentado, a análise do tripé de madeira foi inconclusiva. Primeiramente, foi impossível analisar a origem da estrutura do artefato. Por ser deveras comum em diversas plataformas, tal estrutura pode ter pertencido a inúmeros conjuntos de objetos 


\section{Revista de Arqueologia Pública}

impossíveis de serem identificados nesta pesquisa. O objetivo para o novo uso do objeto (se realmente existiu um novo uso) pode ter possibilidades infinitas. Conforme Neustupný (1993 p., 47),

Quando um artefato deixa a esfera da cultura viva ao ser descartado, por exemplo, ele volta à esfera dos objetos naturais: eles perdem qualquer função, significado ou significância, e sua organização formal ou espacial desintegra-se. Consequentemente, a informação que ele carrega diminui, e a entropia aumenta. O processo é irreversível: a informação perdida não pode ser recuperada dos artefatos desintegrados.

Neustupný disserta que objetos como este tripé de madeira tinham sua funcionalidade específica, mas depois de "mortos socialmente", perderam o teor de sua função original. Ponderar sobre a função do objeto após sua "morte social" seria mera especulação. $O$ tripé provavelmente não era utilizado há muito tempo, pois os dois parafusos contidos em sua estrutura apresentaram claros sinais de ferrugem. Os sinais de depredação animal também se tornaram presentes ao longo do artefato.

\section{Bola emborrachada}

Conforme apresentado anteriormente, tal objeto é de natureza única não só no sítio "Cama", mas também no entorno, onde não há outros sinais ou indícios de brinquedos ou objetos destinados a crianças. O objeto encontrava-se dentro dos limites do sítio e, possivelmente, não era usado de maneira contínua pelos moradores. O motivo de não ter sido descartado de maneira efetiva pode ser explicado pela sua diminuta dimensão. Tal objeto pode ter "escapado" da vista de seus moradores e, por ser um artefato de forma esférica, é possível ter se deslocado acidentalmente para o sítio "Cama" sem o percebimento de seus habitantes.

O artefato também apresenta sinais de atividade depredadora animal, estando parcialmente danificado, possivelmente por mordidas. Não é possível imaginar um outro uso para o objeto, a não ser o qual ele próprio se define em seu conceito: um instrumento de recreação, de lazer ou exercícios físicos. Podemos sugerir que é possível que os moradores do apartamento nem tivessem consciência que tal objeto estivesse no sítio, ou talvez então, nem se lembrassem dele. Há a possibilidade também que o artefato não pertencesse aos moradores e estava "perdido" debaixo do sítio cama. Não foi possível estabelecer uma datação para o artefato.

\section{Caixa de CDs e Caixa de Fitas Cassete}

Tais artefatos foram analisados juntos devido à sua relação e tipologia "musical". O artefato caixa de CDs apresentava muitos produtos originais, como aqueles adquiridos em lojas ou locais licenciados, e também mídias graváveis, nas quais foram digitalizadas músicas. Há também um pequeno número de mídias denominadas DVDs regraváveis na caixa. Um fator comum entre as diferentes mídias são a natureza de seu conteúdo: há apenas músicas gravadas. CDs ou DVDs com filmes, dados documentais ou quaisquer outros tipos de arquivo não foram encontrados. Podemos 


\section{Revista de Arqueologia Pública}

estabelecer que a datação pertença a um período relacionado entre os anos $1990^{2}$, data provável em que as mídias graváveis e regraváveis começaram a ser comercializadas no Brasil, até o presente.

Para o outro artefato, caixa de fitas cassete, pode-se estabelecer uma datação no período entre 1964 (ano em que o produto começou a ser produzido de maneira massificada) até início dos anos 90 , data em que o produto deixou de ser fabricado ${ }^{3}$. 0 apartamento, porém, conforme informação obtida durante o levantamento documental, foi construído no ano de 1998, e provavelmente ocupado em uma datação próxima.

Pode-se pensar que os moradores tivessem estes objetos antes de morarem nesta residência, trazendo-os de seus lares anteriores, ou então adquiriram as mídias como uma forma de antiguidade. As mídias são de naturezas diversas: muitas originais, pertencentes a diversos artistas e adquiridas em estabelecimentos comerciais, outras são gravadas de maneira doméstica. Assim como as mídias de CDs e DVDs, os registros gravados em fita cassete são relacionados somente a músicas, não há nelas quaisquer outros dados a não ser os musicais.

O fato das mídias (tanto os CDs, DVDs, e fitas cassetes) encontrarem-se no sítio determina que não são frequentemente usadas. Podemos estabelecer que após os anos 90 iniciou-se uma revolução musical nos formatos de mídia. Tradicionais formas de áudio foram substituídas pela mídia $\mathrm{mp}^{4}$, com características digitais que permitem que elas sejam armazenadas em diminutos recipientes (como celulares, aparelhos reprodutores de mp3, pendrives, etc.), ou então em aparelhos maiores (em microcomputadores, notebooks, etc.). O fato de não haver descarte definitivo destas mídias pode ser explicado das seguintes maneiras: 1) os moradores tinham em suas mídias gravações que não conseguiram obter de maneira digital; 2) os moradores poderiam ter apreço em colecionar objetos antigos; 3) talvez os moradores ainda tivessem objetos reprodutores de mídia antigos; e 4) poderia haver alguma relação sentimental com as mídias antigas que não permitisse aos moradores descartálas.

As caixas em que as mídias foram encontradas eram de papelão, e também estavam danificadas pela ação animal.

\section{CONSIDERAÇÕES FINAIS}

Nessa última etapa do trabalho, após a avaliação do material selecionado, foi possível chegar a algumas considerações. A primeira é que as pessoas que habitavam o apartamento possuíam um ou mais animais de estimação. Os constantes registros de mordeduras e arranhões em diversas plataformas, como a tábua de passar roupas, o tripé de madeira, a bola de plástico ou a caixa de papelão que abrigava as mídias corroboram esta hipótese. $\mathrm{O}(\mathrm{s})$ animal(is) deveria(m) ser de pequeno

\footnotetext{
2 História do CD, em http://www.duplimaster.com/po_historia.php. Acessado em 07.jun.2012 ${ }^{3}$ Lado B. A História das Fitas-Cassetes, em http://obviousmag.org/ archives/2011/10/lado_b_a_historia_das_fitas-cassetes.html. Acessado em 07.jun.2012

${ }^{4}$ A História do MP3, em http://www.tecmundo.com.br/player-de-audio/2106-a-historia-do-mp3.htm. Acessado em 07.jun.2012
} 


\section{Revista de Arqueologia Pública}

porte, possivelmente um ou mais gatos. O tamanho diminuto do animal justifica-se primeiramente pelas dimensões do ambiente. Sendo um apartamento pequeno, não seria um ambiente propício para um animal de grande estatura. E o próprio sítio, com uma altura de $47 \mathrm{~cm}$ (tamanho entre o chão e a parte superior da camada colchão), disponibilizava uma passagem de apenas $20 \mathrm{~cm}$ (altura entre o chão e a parte inferior da estrutura da cama) que não possibilitaria a entrada de um grande animal dentro de seus domínios.

Dentre os animais domésticos que convivem com humanos em apartamentos, os mais comuns são gatos e cães de pequeno porte. Existem exceções, como furões, coelhos, ratos e chinchilas, entre outros, mas tais animais vivem normalmente em gaiolas e não costumam transitar pelo imóvel. A hipótese de ser um ou mais gatos que residiam no imóvel junto com os moradores é maior que a possibilidade de cães devido aos arranhões encontrados. As unhas de cães são mais grossas que a dos gatos, mesmo tratando-se de cães de pequeno porte. As dilacerações encontradas nos artefatos e entendidas como arranhões remetem-se mais aos parâmetros felinos. Possivelmente, a bola emborrachada, tão fora de seu contexto no sítio, pertencia a um animal de estimação, que brincava com o artefato nos limites do sítio "Cama".

Outra discussão possibilitada pela nossa pesquisa refere-se ao conceito de consumo. Discutimos que possivelmente novas formas de mídia substituíram as anteriores, os CDs e fitas cassete. Porém, as antigas mídias não foram descartadas. Pode-se verificar a convivência de padrões antigos de culturas com padrões mais contemporâneos. Não se pode afirmar se tais mídias eram usadas ou não (mais uma vez pensando em Childe e seu conceito de associados), mas seus valores não foram deixados de lado pelos moradores, que resolveram não descartar os objetos de maneira definitiva. A era da digitalização da mídia facilitou, e muito, o acesso à música em geral, tornando esta arte democratizada, mas também banalizada: ao mesmo tempo em que a maioria das pessoas teve acesso gratuito à informação, a obtenção desta informação tornou-se massificada, resultando em uma drástica mudança no que diz respeito ao consumo e contexto do produto. Ao deixar de comprar uma mídia "oficial", comercializada em lojas, e adquirir este tipo de cultura gratuitamente em downloads na internet, o público em geral começou a se distanciar do artista, não se importando mais com as capas dos CDs, os encartes, quem produziu determinada música ou o produto CD em si. O que importava, a partir deste momento, era o consumo imediato da música. É provável que as pessoas que residissem no apartamento demonstrassem um apreço pela maneira antiga do conceito de mídia, e atribuam uma valorização maior a outros aspectos do produto (capa, encarte, artista, etc.). Ou simplesmente por uma ligação emocional não foram capazes de se desfazer definitivamente destes itens.

Quanto à tábua de passar roupas e o tripé de madeira, não foi possível chegar a uma solução satisfatória. Uma hipótese provável é que tais objetos, por estarem localizados nas quadrículas 1 e 2, situavam-se em local de acesso mais difícil aos moradores (diferentemente das quadrículas 3 e 4, que não tinham como limite as paredes do dormitório) e foram esquecidos. Objetos de uso doméstico

dificilmente apresentam valor sentimental aos donos e são descartados facilmente quando a tecnologia 


\section{Revista de Arqueologia Pública}

os substitui por outros objetos. A permanência destes objetos no sítio não condiz com padrões de consumo destinados a esses tipos de objetos.

Porém, de uma maneira geral, esta pesquisa possibilitou a reconstrução parcial de alguns costumes cotidianos dos moradores deste apartamento. Tais habitantes não se relacionavam com todos os locais existentes na residência. A tábua de passar roupas, em estado irreversível de degradação, não fora descartada, possivelmente por esquecimento, assim como o tripé de madeira. As ações destrutivas do(s) animal(is) de estimação, em quase todos os objetos do sítio, pressupõe que o local não era monitorado ou usado constantemente pelos moradores. Talvez o advento da vida contemporânea, onde o homem, de uma maneira geral, dedica a maior parte de seu tempo ao sustento econômico, justifique o "abandono parcial" de determinado espaço do seu lar. E por último, vale ressaltar a coexistência de mídias de diferentes tempos históricos mostrando que, apesar de todo o advento digital, algumas formas de disseminação cultural ainda sobrevivem após seu tempo. Mesmo que estas mídias mais antigas não sejam usadas, elas continuam vivas para nos contar suas histórias.

\section{ARQUEOLOGIA PÚBLICA}

Nesta etapa, talvez uma das mais importantes do trabalho, disponibilizamos os achados do sítio para a população. A arqueologia muitas vezes aparece como uma disciplina distante do cotidiano popular, sendo mensurada como uma vertente pertencente à elite. O principal intuito arqueológico é resgatar parte de determinado passado e colocar este conhecimento ao público.

Após todas as etapas - classificação, ordenação e avaliação - os objetos foram colocados no saguão do prédio, em exposição. Foi organizado junto com a equipe administrativa do edifício um encontro na forma de debate com os moradores do prédio, para assim explicar o trabalho feito, a metodologia usada, a importância dos objetos encontrados e de que maneira podemos entender a vida social do homem através dos restos deixados para trás. Afinal, como disse Trigger (2004, p. 3) "a reação do público aos achados de arqueologia é um indicativo da necessidade de enquadrar sua história em um amplo contexto social".

\section{REFERÊNCIAS BIBLIOGRÁFICAS}

CHILDE, G. Para uma Recuperação do Passado. São Paulo: Ed. Difel, 1969.

DREWETT, P. Field Archaeology - An Introduction. USA: Ed. Taylor \& Francis, 1999.

NEUSTUPNÝ, E. Archaeological Method. Cambridge: Cambridge University Press, 1993.

TRIGGER, B. G. História do Pensamento Arqueológico. Ed. Odysseus, 2004.

\section{Sites consultados:}

HAUTSCH, Oliver. "A História do mp3". Disponível em <http://www.tecmundo.com.br/player-deaudio/2106-a-historia-do-mp3.htm>. Acessado em: 07.jun.2012

História do CD Disponível em http://www.duplimaster.com/po_historia.php. Acessado em 07.jun.2012 


\section{Revista de Arqueologia Pública}

Lado B. "A história das fitas-cassestes". Disponível em <http://obviousmag.org/ archives/2011/10/lado_b_a_historia_das_fitas-cassetes.html>. Acessado em 07.jun.20 